\title{
Genetic Diversity of Major Greek Olive Cultivars Using Molecular (AFLPs and RAPDs) Markers and Morphological Traits
}

\author{
Marianna Hagidimitriou ${ }^{1}$ \\ Pomology Laboratory, Department of Crop Science, Agricultural University of Athens, Iera Odos 75, \\ 11855 Athens, Greece \\ Andreas Katsiotis \\ Plant Breeding \& Biometry Laboratory, Department of Crop Science, Agricultural University of Athens, \\ Iera Odos 75, 11855 Athens, Greece
}

\author{
George Menexes \\ Department of Applied Informatics, University of Macedonia, Thessaloniki, Greece
}

Constantinos Pontikis

Pomology Laboratory, Department of Crop Science, Agricultural University of Athens, Iera Odos 75, 11855 Athens, Greece

Michael Loukas

Genetics Laboratory, Department of Agricultural Biotechnology, Agricultural University of Athens, Iera Odos 75, 11855 Athens, Greece

\begin{abstract}
AdDITIONAL INDEX wORDS. Olea europaea, genetic relationships, polymorphism, UPGMA, Olea chrysophylla, PCA
Abstract. The aim of the present study was to develop a reliable reference database to discriminate between the major Greek olive (Olea europaea L.) cultivars and reveal their genetic relationships, since Greece is considered a secondary center of diversity. In order to establish genetic relationships among the 26 Greek and eight international cultivars, four amplified fragment length polymorphism (AFLP) primer pairs, 12 randomly amplified polymorphic DNA (RAPD) primers, along with measurements from 10 morphological traits, were used. A total of 576 AFLP and 113 RAPD markers were produced. Genetic similarities, estimated using the Jaccard algorithim, ranged from 0.45 to 0.83 for the AFLP data and 0.27 to 0.87 for the RAPD data. The cophenetic correlation coefficients between the genetic similarities and the unweighted pair group method of arithmetic averages (UPGMA) phenograms were 0.77 for the AFLPs, 0.81 for the RAPDs, and 0.69 for the morphological traits. However, limited clustering similarities among the phenograms derived from the three methods were observed. This was also reflected by the low correlation between the three genetic similarity matrices produced (AFLP and RAPD, $r=0.39$; AFLP and morphological traits, $r=0.11$; RAPD and morphological traits, $r=0.02$ ). According to the molecular results, olive cultivars are clustered according to fruit size but not according to geographical origin. Three of the cultivars tested, 'Vasilicada,' 'Throumbolia', and 'Lianolia Kerkiras', were found to branch distantly to the others, according to the AFLP results, and can be considered as ancient Greek cultivars.
\end{abstract}

Olive is one of the most ancient cultivated fruit tree species in the Mediterranean Basin, with great socioeconomic impact for the countries present in the area. Description and characterization of the genetic resources of such an important clonally propagated crop should provide the extent of its diversity, geographical spread and domestication, and help with decision making in breeding programs. Furthermore, cultivar certification is required for nursery propagated clones to maintain and control quality of oil and table olives, and for identifying synonyms. During the last 5 years, a considerable effort has been undertaken to fingerprint and describe the genetic diversity of O. europaea from Italy (Rotondi et al., 2003), France (Khadari et al., 2003), Spain (Belaj et al., 2001), Israel (Wiesman et al., 1998), Albania (Belaj et al., 2003a), Greece (Nikoloudakis et al., 2003), and other Mediterranean countries (Angiolillo et al., 1999; Belaj et al., 2002; Besnard et al., 2001a). In most cases, molecular markers, generated by

Received for publication 12 May 2004. Accepted for publication 10 Aug. 2004. 1To whom reprint requests should be addressed. E-mail : marianna@aua.gr randomly amplified polymorphic DNA (RAPD), amplified fragment length polymorphism (AFLP), and simple sequence repeats (SSR), as well as morphological characteristics, or a combination of more than one of the previous methods, have been used. More than 250 olive cultivars have been described using morphological characteristics, and most of them were also characterized by using molecular markers.

One of the world's leading olive producing countries, either as oil or table, is Greece. Annual production for table olives is more than 80,000 t produced from $\approx 32$ million trees, while more than 350,000 t of oil is produced from $\approx 120$ million trees, covering a total of 729,000 ha (Pontikis, 2000). More than $90 \%$ of the acreage is cultivated with $\approx 20$ cultivars, which are adapted in a wide range of environmental conditions. The total number of Greek cultivars is more than 40 (excluding clonal selections), most of which have evolved and selected over the centuries to match local conditions. The presence of this large number of olive cultivars, adapted to diverse environments, reflects the wealth of genetic resources in the area. The olive tree, which was 
first domesticated in the eastern Mediterranean Basin, moved westward to the Aegean pelagos back to the 16th century BC and was later introduced to the Greek mainland (14th to 12th centuries BC). Thus, Greece is considered a secondary center of diversity (Besnard et al., 2001b; Damania, 1995), while parts of southern Italy and northern Africa became third centers of diversity (Damania 1995). According to Tavanti, in ancient Greece, at least 15 cultivars have been described based on morphological appearance, when, during the same time period, only two were described in Egypt and three in the Middle East (Prevost and Mostardini, 1999). In modern times, 28 Greek olive cultivars have been described in detail using phenological and morphological characters (Anagnostopoulos, 1939; Pontikis, 2000). However, this classification is considered inadequate since these traits are influenced by environmental effects. Furthermore, in many cases these cultivars can have more than one name, and although some of their synonyms have been identified, a degree of confusion still exists over the within-cultivar genetic variation, since the original cultivar plants originated from chance seedlings that have been extensively clonally propagated through the centuries. Currently, each nursery maintains its own mother plants that are adapted to the local environment. To overcome the environmental effect, biochemical markers/isozymes (Pontikis et al., 1980) and RAPD markers (Nikoloudakis et al., 2003) have been used. Low isozyme polymorphism and limited RAPD reproducibility (Jones et al., 1998a) create the need to use a more reliable molecular marker method for developing an olive fingerprinting database.

The aim of the present study was to reveal the genetic relationships among 26 major Greek olive cultivars that are widely used for oil or table production and to develop a reliable reference database for Greek cultivar identification. To accomplish the above goals, AFLP, a reproducible molecular marker method (Jones et al., 1998b), was used. In addition, RAPD markers, a commonly used as a fast and low-cost molecular marker technique, and morphological characteristics were also used and compared to AFLP results.

\section{Materials and Methods}

Plant material. In the present study, 19 major Greek cultivars along with seven cultivars that have regional ('Amigdalolia', 'Gaidourelia', 'Karolia', 'Kalokerida', 'Kolimpada', and 'Tragolia') or ornamental ('Asprolia') importance were included (Table 1). Furthermore, eight introduced $O$. europaea cultivars from Egypt ('Toffahi'), Algeria ('Sigoise'), Spain ('Nevadillo Negro,' 'Nevadillo Blanco', 'Gordal', and 'Lechin'), and Italy ('St. Agostino' and 'Frantoio'), along with Olea chrysophylla Lam., used as an outgroup, were also included. All of the above-mentioned cultivars are part of the Agricultural Univ. of Athens orchard. Total genomic DNA, for both AFLP and RAPD analyses, was extracted from young leaves following a standard hexadecyltrimethylammonium bromide (CTAB) method (Murray and Thompson, 1980).

AFLP. The AFLPPlant Mapping (Applied Biosystems, Foster City, Calif.) kit was used for the AFLP reactions. Reactions were as previously described by Katsiotis et al. (2003). For preselective amplification, primer pair $E c o \mathrm{RI}+\mathrm{A} / M s e \mathrm{I}+\mathrm{C}$ was used and for selective amplification, four primer pairs were used (Table 2), for which all EcoRI primers were fluorescently labeled. Separation of the selective PCR products was done with an ABI Prism 310 Genetic Analyzer (Applied Biosystems). Results were scored and analyzed using GeneScan and Genotyper (Applied Biosystems) softwares, respectively.
RAPD. Twelve RAPD primers were selected (Table 3) from a set of 20 different 10-mer primers. Each reaction contained polymerase chain reaction (PCR) buffer (20 mu tris- $\mathrm{HCl} \mathrm{pH} \mathrm{8.4,} 50$ $\mathrm{mm} \mathrm{KCl}$ ), $100 \mathrm{ng}$ of DNA, $0.27 \mathrm{~mm}$ of each dNTP, $3 \mathrm{~mm} \mathrm{MgCl}$, $0.20 \mu \mathrm{m}$ of primer, and $1 \mathrm{U}$ of Taq DNA polymerase (Invitrogen, Carlbad, Calif.), at a final volume of $30 \mu \mathrm{L}$. Thermocycling conditions were: an initial step of $94{ }^{\circ} \mathrm{C}$ for $2 \mathrm{~min}$, followed by 30 cycles of $94{ }^{\circ} \mathrm{C}$ for $45 \mathrm{~s}, 40{ }^{\circ} \mathrm{C}$ for $1 \mathrm{~min}, 72^{\circ} \mathrm{C}$ for $2 \mathrm{~min}$, with a final elongation step at $72{ }^{\circ} \mathrm{C}$ for $7 \mathrm{~min}$. The PCR products were separated on a $1.2 \%$ agarose gel, stained with ethidium bromide, and digitally photographed. The reactions were run twice and only reproducible bands were scored.

MORPHOLOGICAL CHARACTERS. The morphological characters measured, for 26 Greek cultivars, were: tree height, size of the leaves (length and width), weight and shape of the fruit, weight of the stone, presence/absence of the nipple on the fruits and of the mucro on the stones, number of the grooves on the stone, and oil yield percentage. Fruit weight relates to fruit size, forming three categories: small-, medium-, and large-fruited trees. Two of the measurements were binary, two were ordinal, and six were continuous (Table 1).

Data ANALYSIS. Genetic similarities (GS) for the AFLP and RAPD data were calculated using the Jaccard algorithm, and phenograms were constructed using the clustering method of the unweighted pair group method of arithmetic averages (UPGMA). The cophenetic correlation coefficient (CCC) was used to measure the goodness of fit of the genetic similarity matrices to their corresponding phenograms, while the correlation among all genetic similarity matrices was checked using the Mantel test. All of the above analyses were performed using the NTSYSpc version 2.02i software (Rohlf, 1998).

For morphological data, the principal components analysis (PCA) with Varimax rotation was applied (Hair et al., 1995; Sharma, 1996). The latent root criterion (eigenvalues $>1$ ) was used for determining the number of principal components. The Bartlett's test of sphericity and the Kaiser-Meyer-Olkin measure of sampling adequacy were used to test and determine the factorability of the correlation matrix as a whole. Subsequently, using the regression factor scores for each cultivar, cluster analysis was applied to construct a phenogram, using the Euclidean distance to calculate the similarity matrix and UPGMA. For the morphological analyses, the SPSS software, version 11.5, (Norusis, 1994) was used. The CCC was again used to measure the goodness of fit of the similarity matrix to the corresponding UPGMA dendrogam.

\section{Results}

Both molecular methods generated enough polymorphism to discriminate the 34 cultivars (Figs. 1 and 2). The four AFLP primer pairs amplified a total of 576 DNA fragments, ranging from 82, for primer pair EcoACT/CACMse, to 247, for primer pair EcoAAG/ACTMse (Table 2). Thus, each cultivar show enough polymorphism when a single AFLP primer pair is used, leading to a unique fingerprint for each cultivar and providing a reference database for plant identification. The genetic similarities, excluding outgroup $O$. chrysophylla, ranged from 0.45 ('Nev. Blanco'-'Gaidourelia') to 0.83 ('Kalamon'-'Kalokerida'). The cultivars were grouped into six clusters using the AFLP data (Fig. 1). The CCC value between the AFLP genetic similarity matrix and the UPGMA clustering method was $\mathrm{r}_{\mathrm{AFLP}}=0.77$. The 12 RAPD primers amplified a total of 113 reproducible polymorphic frag- 
Table 1. Morphological characteristics of major Greek olive cultivars used in the multivariate analysis (Pontikis, 2000).

\begin{tabular}{|c|c|c|c|c|c|c|c|c|c|c|}
\hline Cultivar & $\begin{array}{l}\text { Tree } \\
\text { size }^{\mathrm{z}}\end{array}$ & $\begin{array}{l}\text { Leaf } \\
\text { length } \\
(\mathrm{cm})\end{array}$ & $\begin{array}{l}\text { Leaf } \\
\text { width } \\
(\mathrm{cm})\end{array}$ & $\begin{array}{c}\text { Fruit } \\
\text { shape }^{y}\end{array}$ & $\begin{array}{c}\text { Fruit wt } \\
(\mathrm{g})\end{array}$ & Nipple $^{\mathrm{x}}$ & $\begin{array}{c}\text { Stone } \\
\mathrm{wt} \\
(\mathrm{g})\end{array}$ & Mucro $^{\mathrm{x}}$ & $\begin{array}{c}\text { Grooves } \\
\text { (no.) }\end{array}$ & $\begin{array}{c}\text { Oil yield } \\
(\%)\end{array}$ \\
\hline Agouromanakolia & 2 & 6.5 & 1.3 & 2 & 3.3 & - & 0.47 & - & 8 & 30 \\
\hline Adramitini & 2 & 5.83 & 1.43 & $4 / 2$ & 3.5 & - & 0.54 & + & 10 & 23 \\
\hline Amigdalolia & 1 & 8.17 & 1.31 & 5 & 8.4 & + & 0.73 & - & 7 & 22 \\
\hline Asprolia & 2 & 6.62 & 1.04 & 1 & 0.6 & - & 0.17 & + & 8 & 12.5 \\
\hline Valanolia & 2 & 6.21 & 1.24 & 5 & 5.1 & - & 0.65 & - & 9 & 25 \\
\hline$\underline{\text { Vasilikada }}$ & 2 & 6.35 & 1.13 & 2 & 6.0 & - & 0.7 & + & 9 & 16 \\
\hline Gaidourelia & 1 & 7.35 & 1.30 & 5 & 10.5 & - & 0.98 & + & 10 & 17 \\
\hline Dafnelia & 4 & 5.3 & 1.0 & 1 & 2.7 & + & 0.62 & + & 8 & 19 \\
\hline Thiaki & 1 & 5.86 & 1.50 & $2 / 1$ & 1.6 & + & 0.23 & + & 8 & 21 \\
\hline Kalamon & 2 & 8.48 & 1.64 & 6 & 5.6 & - & 0.60 & - & $9-10$ & 17 \\
\hline Kalokerida & 3 & 5.8 & 1.2 & 2 & 3.2 & + & 0.37 & + & 8 & 22 \\
\hline Karolia & 2 & 6.43 & 1.33 & 5 & 7.6 & - & 0.86 & + & 10 & 17 \\
\hline Karidolia & 1 & 6.94 & 1.40 & 1 & 5.8 & + & 0.7 & + & 10 & 14 \\
\hline Kothreiki & 1 & 5.68 & 1.36 & $2 / 3$ & 4.7 & - & 0.70 & + & 7 & 20 \\
\hline Kolimpada & 1 & 6.57 & 1.13 & 3 & 6 & + & 1.15 & - & $6-7$ & 19 \\
\hline Konservolia & 2 & 7.40 & 1.29 & $2 / 3$ & 5.7 & - & 0.51 & + & 7 & 16 \\
\hline Koroneiki & 1 & 5.47 & 1.03 & 1 & 1.3 & + & 0.17 & + & 7 & 27 \\
\hline Koutsourelia & 1 & 3.95 & 0.88 & 1 & 1.2 & + & 0.20 & - & $7-8$ & 25 \\
\hline Lianolia Kerkiras & 3 & 6.67 & 1.49 & 1 & 2.3 & + & 0.27 & - & 10 & 19 \\
\hline Mastoeidis & 1 & 6.18 & 1.18 & 2 & 2.6 & + & 0.37 & + & 10 & 20 \\
\hline Mavrelia & 2 & 5.78 & 1.33 & 1 & 1.9 & - & 0.32 & - & 6 & 19 \\
\hline Megaritiki & 1 & 6.64 & 0.93 & 1 & 4.2 & + & 0.42 & - & 10 & 21 \\
\hline Mirtolia & 2 & 3.96 & 0.93 & 2 & 2.3 & - & 0.47 & - & 8 & 24 \\
\hline Strogilolia & 2 & 8.11 & 1.39 & 3 & 4.6 & - & 0.60 & + & 6 & 16 \\
\hline Throumbolia & 2 & 5.69 & 1.24 & 1 & 3.3 & + & 0.53 & + & 9 & 28 \\
\hline Tragolia & 1 & 5.90 & 1.26 & 1 & 2.4 & - & 0.34 & - & 7 & 27.5 \\
\hline
\end{tabular}

zTree size classification: 1 (5-6 m), 2 (5-8 m), 3 (7-10 m), and 4 (10-14 m).

yFruit shape classification: 1 (cylindrical/conical), 2 (cylindrical), 3 (round), 4 (sub-round), 5 (oblong), and 6 (one-sided bend).

xNipple and mucro presence (+) or absence (-) from fruits and stones, respectively.

Table 2. Primer combinations used in the AFLP reactions and number of polymorphic bands obtained for each primer pair from the PCR reactions of the 34 olive cultivars and Olea chrysophylla.

\begin{tabular}{lc}
\hline Primer combination & Polymorphic bands (no.) \\
\hline EcoACT/CACMse & 82 \\
EcoAAG/CTCMse & 94 \\
EcoACT/CTCMse & 153 \\
EcoAAG/ACTMse & 247 \\
\hline Total & 576 \\
\hline
\end{tabular}

Table 3. Codes and sequences of the RAPD primers used and number of polymorphic bands produced from the PCR reactions of the 34 olive cultivars.

\begin{tabular}{llc}
\hline Primer & \multicolumn{1}{c}{ Sequence } & Polymorphic bands (no.) \\
\hline OPAH-09 & 5' AGAACCGAGG 3' & 7 \\
OPAH-12 & 5' TCCAACGGCT 3' & 13 \\
OPAH-16 & 5' CAAGGTGGGT 3' & 10 \\
OPAH-17 & 5' CAGTGGGGAG 3' & 1 \\
OPAH-18 & 5' GGGCTAGTCA 3' & 6 \\
OPAH-19 & 5' GGCAGTTCTC 3' & 11 \\
OPG-05 & 5' CTGAGACGGA 3' & 18 \\
OPH-09 & 5' TGTAGCTGGG 3' & 7 \\
OPAI-05 & 5' GTCGTAGCGG 3' & 14 \\
OPA-9 & 5' GGGTAACGCC 3' & 9 \\
OPA-20 & 5' GTTGCGATCC 3' & 8 \\
OPAI-13 & 5' ACGCTGCGAC 3' & 9 \\
\hline Total & & 113 \\
\hline
\end{tabular}

phic fragments (Table 3 ). The number of polymorphic bands per primer ranged from 1 (OPAH-17) to 18 (OPG-05). The genetic similarities ranged from 0.27 ('Koroneiki'-'Valanolia') to 0.87 ('St. Agostino'-'Konservolia'), forming again six major clusters (Fig. 2), while the CCC value between the genetic similarity matrix and the UPGMAclustering method was $r_{\text {RAPD }}=0.81$. In both cases the $\mathrm{CCC}$ values show a good fit of the molecular generated data to the clustering method. Finally, the estimated CCC between the Jaccard genetic similarity matrix of the combined data (AFLP and RAPD) and the UPGMA clustering method was $\mathrm{r}_{\mathrm{COM}}=0.73$.

The correlation between the AFLP and RAPD genetic similarity matrices was $r=0.39$, indicating a rather poor relationship among the two genetic similarity matrices. Thus, clustering differences are observed between the AFLP and RAPD phenograms. Only a few cultivar pairs remain the same under both methods ('Kalamon'-'Kalokerida', 'Thiaki'-'Koutsourelia', and 'Lianolia Kerkiras'-'Nevadillo Blanco') (Figs. 1 and 2). In general, large/ medium- and medium/small-fruited cultivars tend to be clustered in both phenograms. For the AFLP data (Fig. 1) clusters I, II, and III contain large and medium-fruited cultivars, with the exception of 'Mastoidis,' while clusters IV, V and VI contain medium- and small-fruited cultivars, with the exceptions of 'Kalamon', 'Vasilicada', and 'Toffahi'. In the RAPD phenogram (Fig. 2) clusters I, II, and III contain only large- and medium-fruited cultivars, while clusters IV, V, and VI have small- and medium-fruited cultivars, with the exception of 'Kalamon' and 'Gaidourelia'. Although poor correlation between the AFLP and RAPD genetic similarities is observed, some clusters tend to contain the same 


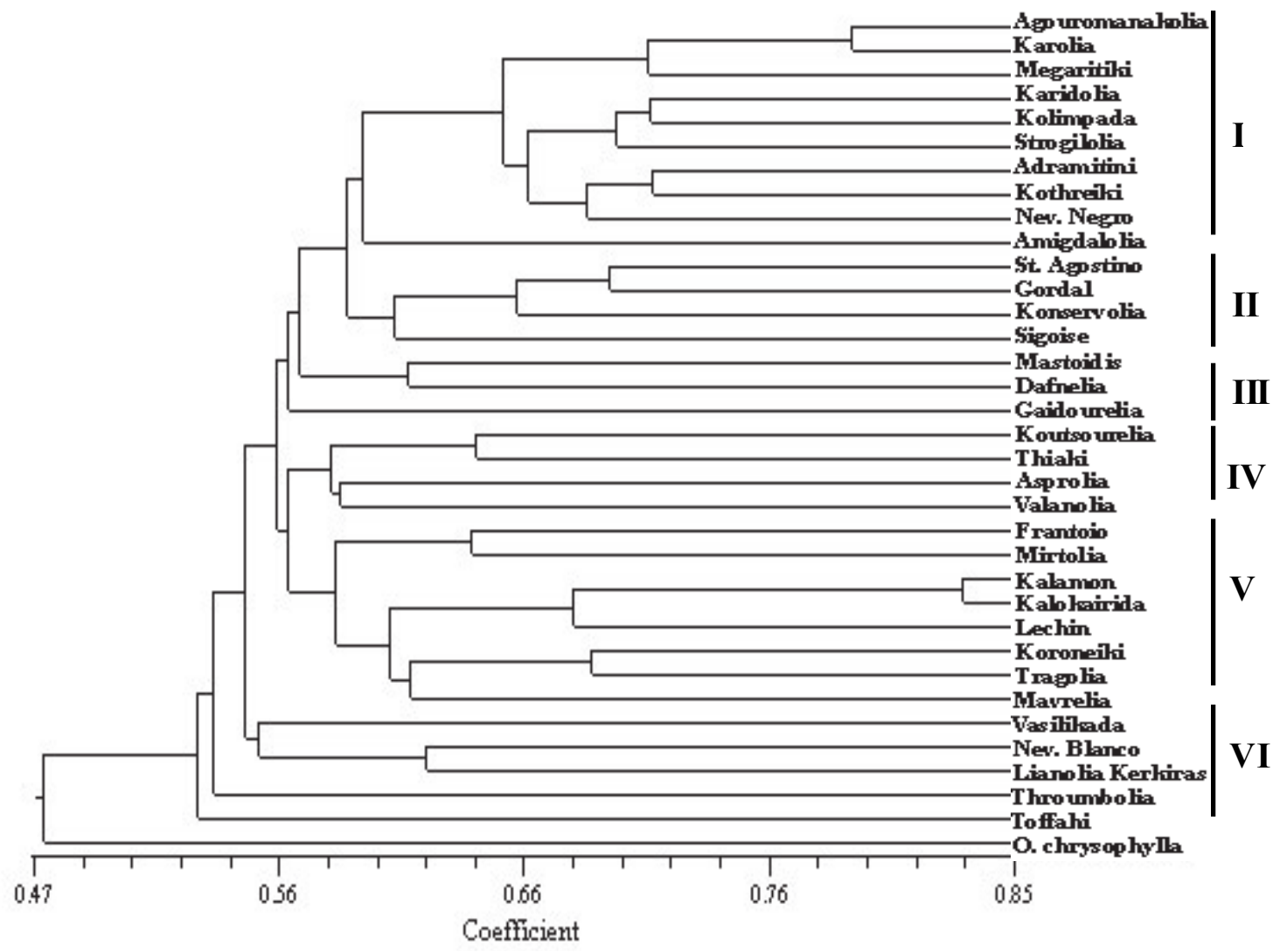

Fig. 1. Phenogram for the Greek and international olive cultivars derived from the 576 polymorphic bands of the AFLP data, using the Jaccard algorithm and the UPGMA clustering method. Roman numerals I through VI indicate clusters designations for grouping the olive cultivars.

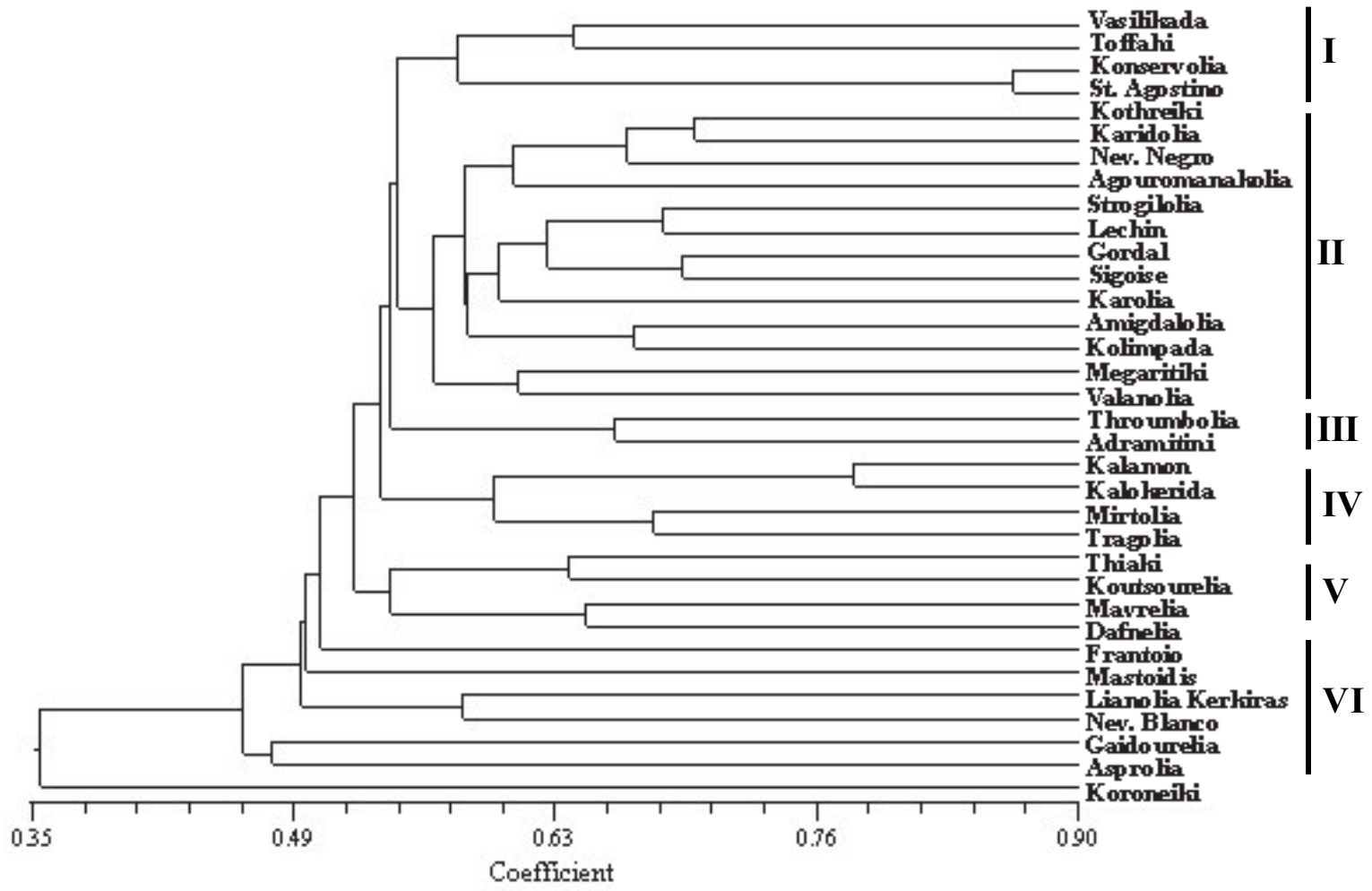

Fig. 2. Phenogram for the Greek and international olive cultivars derived from the 113 polymorphic bands using 12 RAPD primers, the Jaccard algorithm, and the UPGMA clustering method. Roman numerals I through VI indicate clusters designations for grouping the olive cultivars. 
cultivars. Thus, the AFLP cluster I contains most cultivars from the RAPD cluster II, AFLP cluster II has two cultivars in common with RAPD cluster I, AFLP cluster III contains two cultivars from RAPD cluster VI, AFLP cluster IV has two cultivars in common with RAPD cluster V, and AFLP cluster V has four cultivars in common with RAPD cluster IV.

The morphological characters used also discriminated the 25 Greek cultivars checked (Fig. 3). The PCA grouped the variables into four components ( $\mathrm{C} 1$ to $\mathrm{C} 4)$ comprising from: $\mathrm{C} 1$-tree height, fruit weight and shape, and stone weight; C2-leaf width and length; C3-presence/absence of mucro and percent oil content; and C4presence/absence of nipple and number of grooves. These four components explained $74 \%$ of the total variation. The Bartlett's test of sphericity for the overall significance of all correlations within the correlation matrix was found significant $\left(X^{2}=94.776\right.$, $\mathrm{df}=45, P=0.000$ ), while the Kaiser-Meyer-Olkin measure of sampling adequacy was 0.61 , more than the 0.50 (Hair et al., 1995) and/or the 0.60 (Coakes and Steed, 1999; Sharma, 1996) levels, which are widely considered as the minimum acceptable values in order to assume factorability. The CCC value between the genetic similarity matrix estimated from the morphological characters and the UPGMA clustering method was $\mathrm{r}_{\mathrm{MOR}}=0.69$, showing a poorer fit compared to the molecular generated data. According to the phenogram (Fig. 3), five clusters are obtained. Clusters I and III contain small to medium fruit size cultivars, with the exception of 'Karidolia' in cluster III, while clusters II and IV contain large fruit size cultivars. However, no clustering similarities are observed to the RAPD and AFLP phenograms. This is also reflected by the low correlation between either the morphological and RAPD similarity matrices $(r=0.02)$ or the morphological and AFLP similarity matrices $(r=0.11)$.

\section{Discussion}

During the last 5 years, a considerable effort to describe molecularly the olive genetic resources from different Mediterranean countries was initiated, but in all cases Greek cultivars were underrepresented. In the present study we concentrated on Greek olive cultivars since the Aegean area is considered a secondary center of diversity (Damania, 1995) and because no particular geographic clustering was observed for eight Greek cultivars when used along with 96 diverse material (Besnard et al., 2001a), reflecting the olive genetic variability in the area.

According to the CCC values calculated $\left(\mathrm{r}_{\mathrm{RAPD}}=0.81\right.$ and $\mathrm{r}_{\mathrm{AFLP}}=$ 0.77 ), both phenograms derived from the molecular data represent accurately cultivar relationships. These values are higher than a number of similar studies done in olives [Fabbri et al., $1995\left(\mathrm{r}_{\mathrm{RAPD}}\right.$ $=0.79)$; Belaj et al., $2002\left(\mathrm{r}_{\mathrm{RAPD}}=0.61\right)$; Guerin et al., $2002\left(\mathrm{r}_{\mathrm{RAPD}}\right.$ $=0.67)$; Belaj et al., 2003b $\left(\mathrm{r}_{\mathrm{AFLP}}=0.66\right)$; Belaj et al., 2003a $\left(\mathrm{r}_{\mathrm{RAPD}}\right.$ $=0.68)$ ] but lower than $r_{\text {RAPD }}=0.92$ reported by Nikoloudakis et al. (2003). However, the low correlation calculated between the two similarity matrices $(r=0.39)$ was reflected also by the minor clustering similarities between their corresponding phenograms. Belaj et al. (2003b) also reported a low correlation when comparing olive RAPD and AFLP derived similarity matrices $(r=0.40)$. Correlation between genetic similarities generated by molecular methods range from $r=0.12$, for olives (Belaj et al., 2003b) using SSRs and AFLPs, to $r=0.96$, for garlic (Allium sativum L.) (Ipek et al., 2002) using AFLPs and RAPDs.

Both molecular methods used group the cultivars according to their fruit size (Figs. 1 and 2) and their usage, since large-fruited cultivars are used mainly as table olives and small-fruited cultivars for oil extraction. This observation is in agreement with previous

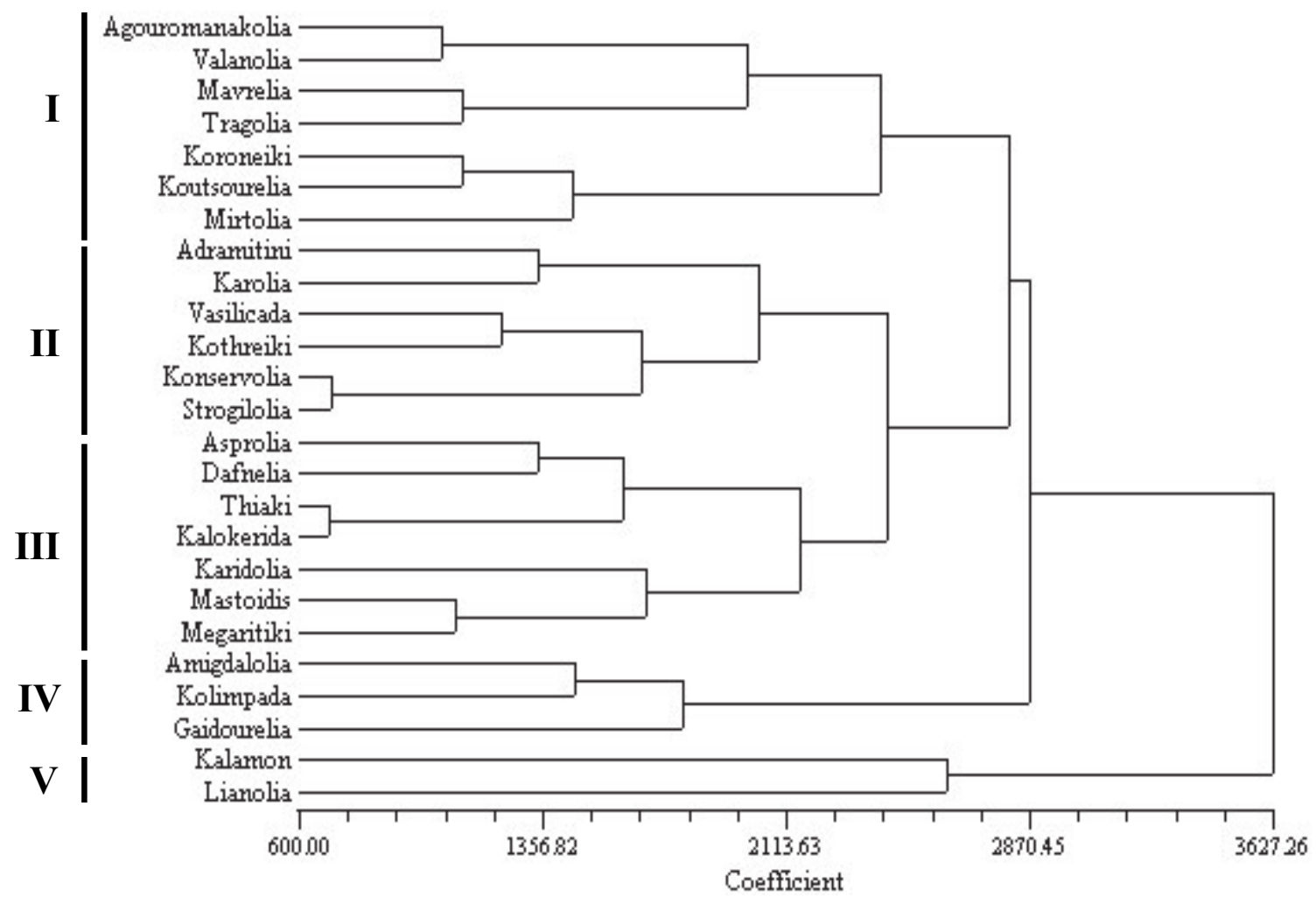

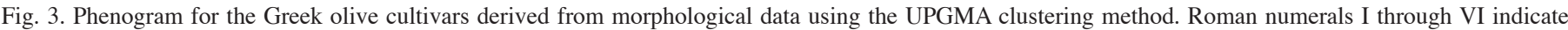
clusters designations for grouping the olive cultivars. 
isozyme (Pontikis et al., 1980; Loukas and Kribas, 1983) and DNA-based (Besnard et al., 2001a) studies. However, no clustering similarities were observed between the present study and the isozyme study (Loukas and Kribas, 1983), where some cultivars were in common. Low correlation $(r=0.34)$ has been reported between isozyme and DNA-based derived data (Heun et al., 1994), while higher correlation $(r=0.89)$ has been obtained only when entries from more than one species were present (Bartish et al., 2000). Geographical origin of the cultivars had no effect on clustering, since cultivars originating from the same country belonged to different clusters. Even cultivars of Greek origin did not show any clustering according to their principal area of cultivation (Figs. 1 and 2). Cultivars Adramitini and Valanolia, both cultivated in the island of Lesvos, are found in clusters I and IV in the AFLP dendrogram and clusters III and II in the RAPD dendrogram, respectively. In addition, cultivars Throumbolia and Dafnelia, both cultivated in the islands of Chios and Samos, are found in clusters VI and III in the AFLP dendrogram and clusters III and V in the RAPD dendrogram, respectively. Absence of regional clustering has also been reported in other perennial crops such as Malus sieversii Lebed. (Lamboy et al., 1996). Thus, olive cultivars fulfill the statement that woody perennial outcrossing species with a widespread geographical distribution maintain most of their variation within populations and display a greater diversity than those with a limited distribution range (Hamrick, 1994). As expected, O. chrysophylla (Chrysolia), the outgroup species used in the AFLP analysis, is clustered to the rest of the O. europaea entries (Fig. 1).

Three cultivar pairs remained the same in both dendograms, 'Kalamon'-'Kalokerida', 'Thiaki'-'Koutsourelia', and 'Lianolia Kerkiras'-'Nevadillo Blanco'. The first pair had a high genetic similarity estimate using either method $(0.78$ for RAPD and 0.83 for AFLP) leading to the conclusion that the two cultivars are related, despite the fact that morphological differences exist between them. On the contrary, 'Thiaki' and 'Koutsourelia' have morphological characters in common, while 'Lianolia Kerkiras' and 'Nevadillo Blanco' are both oil-producing cultivars. However, phenogram interpretation should be done cautiously, since they do not always reflect pedigree or provenance of genotypes (Oraguzie et al., 2001). According to AFLP calculated genetic similarities, cultivars Vasilicada, Lianolia Kerkiras, and Throumbolia, all belonging to group VI, are considered among the most ancient Greek olive cultivars. 'Vasilikada' was actually known by the Romans and was cultivated in the area of Piceno (Lychnos, 1948). Prevost and Mostardini (1999) also consider it as one of the oldest known cultivars. 'Lianolia Kerkiras', according to Lychnos (1948), is a selection from a wild plant present in the Ionian island of Corfu, while 'Throumbolia' is cultivated mainly in the north Aegean island of Thasos and could be related to the introduced germplasm dating back to the16th century BC.

Morphological characters showed a very low correlation with the molecular data. This could be due to the limited number of characters that were selected and measured. In a similar study characterizing the Italian olive cultivars (Rotondi et al., 2003), 16 morphological variables were used but no correlation coefficient was calculated between the molecular and the morphological data. It was also supported that morphological traits were not reliable in estimating genetic relationships among large and diverse groups of cultivars and should be used mainly for discrimination.

In conclusion, a high level of polymorphism exists among the Greek olive cultivars, supported by the genetic distances estimated among them and the diverse material originating from Egypt,
Algeria, Italy and Spain. The absence of geographical clustering, either between countries or according to their principal area of cultivation within countries, reflects the exchange of plant material through the olive cultivation history that could be the result of conscious exchange and cultivation of olive gemrplasm and/or the spontaneous germination of olive stones from traded and imported fruits.

\section{Literature Cited}

Anagnostopoulos, P. 1939. Cultivars and ecology of the Greek olive (in Greek). Lambropoulos Publ., Athens, Greece.

Angiolillo, A., M. Mencuccini, and L. Baldoni. 1999. Olive genetic diversity assessed using amplified fragment length polymorphisms. Theor. Appl. Genet. 98:411-421.

Bartish, I.V., L.P. Garkava, K. Rumpunen, and H. Nybom. 2000. Phylogenetic relationships and differentiation among and within populations of Chaenomeles Lindl. (Roseceae) estimated with RAPDs and isozymes. Theor. Appl. Genet. 101:554-563.

Belaj, A., Z. Satovic, H. Ismaili, D. Panajoti, L. Rallo, and I. Trujillo. 2003a. RAPD genetic diversity of Albanian olive germplasm and its relationships with other Mediterranean countries. Euphytica 130:387-395.

Belaj, A., Z. Satovic, G. Cipriani, L. Baldoni, R. Testolin, L. Rallo, and I. Trujillo. 2003b. Comparative study of the discriminating capacity of RAPD, AFLP and SSR markers and their effectiveness in establishing genetic relationships in olive. Theor. Appl. Genet. 107:736-744.

Belaj, A., Z. Satovic, L. Rallo, and I. Trujillo. 2002. Genetic diversity and relationships in olive (Olea europaea L.) germplasm collections as determined by randomly amplified polymorphic DNA. Theor. Appl. Genet. 105:638-644.

Belaj, A., I. Trujillo, R. de la Rosa, L. Rallo, and M.J. Giménez. 2001. Polymorphism and discrimination capacity of randomly amplified polymorphic markers in an olive germplasm bank. J. Amer. Soc. Hort. Sci. 126:64-71.

Besnard, G., C. Breton, P. Baradat, B. Khadari, and A. Bervillé. 2001a. Cultivar identification in olive based on RAPD markers. J. Amer. Soc. Hort. Sci. 126:668-675.

Besnard, G., P. Baradat, C. Breton, B. Khadari, and A. Bervillé. 2001b. Olive domestication from structure of oleasters and cultivars using nuclear RAPDs and mitochondrial RFLPs. Genet. Selection Evolution 33 (Suppl. 1):S251-268.

Coakes, S. and L. Steed. 1999. SPSS analysis without anguish. Wiley, Singapore.

Damania, A.B. 1995. Olive, the plant of peace, reigns throughout Mediterranean. Diversity 11:131-132.

Fabbri, A., J.I. Hormaza, and V.S. Polito. 1995. Random amplified polymorphic DNA analysis of olive (Olea europaea L.) cultivars. J. Amer. Soc. Hort. Sci. 120:538-542.

Guerin, J.R., S.M. Sweeney, G.G. Collins, and M. Sedgley. 2002. The development of a genetic database to identify olive cultivars. J. Amer. Soc. Hort. Sci. 127:977-983.

Hair, J., R. Anderson, R. Tatham, and W. Black. 1995. Multivariate data analysis with readings, $4^{\text {th }}$ ed. Prentice-Hall, Upper Saddle River, N.J.

Hamrick, J.L. 1994. Genetic diversity and conservation in tropical forests, p. 1-9. In: R.M. Drysdale, S.E.T. John, and A.C. Yapa (eds.). Proc. Intl. Symp. on Genetic Conservation and Production of Tropical Forest Tree Seed. Assn. Southeast Asian Nations-Canada Forest Tree Seed Centre Project. 14-16 June 1993, Muak-Lek, Saraburi, Thailand.

Heun, M., J.P. Murphy, and T.D. Philips. 1994. A comparison of RAPD and isozyme analyses for determining the genetic relationships among Avena sterilis L. accessions. Theor. Appl. Genet. 87:689-696.

Ipek, M., A. Ipek, and P.W. Simon. 2002. Comparison of AFLPs, RAPD markers, and isozymes for diversity assessment of garlic and detection of putative duplicates in germplasm collections. Can. J. For. Res. $32: 246-252$. 
Jones, C.J., K.J. Edwards, S. Castiglione, M.O. Winfield, F. Sala, C. van der Wiel, B.L. Vosman, M. Matthes, A. Daly, R. Brettschneider, P. Bettini, M. Buiatti, E. Maestri, N. Marmiroli, R.L. Aert, G. Volckaert, J. Rueda, A. Vazquez, and A. Karp. 1998a. Reproducibility testing of RAPDs by a network of European laboratories, p. 176-179. In: A. Karp, P.G. Isaac, and D.S. Ingram (eds.). Molecular tools for screening biodiversity: Plants and animals. Chapman \& Hall, London.

Jones, C.J., K.J. Edwards, S. Castiglione, M.O. Winfield, F. Sala, C. van der Wiel, B.L. Vosman, M. Matthes, A. Daly, R. Brettschneider, E. Maestri, N. Marmiroli, R.L. Aert, G. Volckaert, and A. Karp. 1998b. Reproducibility testing of AFLPs by a network of European laboratories, p. 191-192. In: A. Karp, P.G. Isaac, and D.S. Ingram (eds.). Molecular tools for screening biodiversity: Plants and animals. Chapman \& Hall, London.

Katsiotis, A., M. Hagidimitriou, A. Drossou, C. Pontikis, and M. Loukas. 2003. Genetic relationships among species and cultivars of Pistacia using RAPDs and AFLPs. Euphytica 132:279-286.

Khadari, B., C. Breton, N. Moutier,J.P. Roger, G. Besnard,A. Bervillé, and F. Dosba. 2003. The use of molecular markers for germplasm management in a French olive collection. Theor. Appl. Genet. 106:521-529.

Lamboy, W.F., J. Yu, P.L. Forsline, and N.F. Weeden. 1996. Partitioning of allozyme diversity in wild populations of Malus sieversii $\mathrm{L}$. and implications for germplasm collection. J. Amer. Soc. Hort. Sci. 121:982-987.

Loukas M. and C.B. Krimbas. 1983. History of olive cultivars based on their genetic distances. J. Hort. Sci. 58:121-127.

Lychnos, N.D. 1948. The olive tree and its culture (in Greek). PetsalisVallianatos Publ., Athens, Greece.
Murray, M.G. and W.F. Thompson. 1980. Rapid isolation of high weight plant DNA. Nucl. Acid Res. 8:4321-4325.

Nikoloudakis, N., G. Banilas, F. Gazis, P. Hatzopoulos, and J. Metzidakis. 2003 Discrimination and genetic diversity among cultivated olives of Greece using RAPD markers. J. Amer. Soc. Hort. Sci. 128:741-746.

Norusis, M. 1994. SPSS professional statistics 6.1. SPSS, Chicago.

Oraguzie, N.C., S.E. Gardiner, H.C.M. Basset, M. Stefanati, R.D. Ball, V.G.M. Bus, and A.G. White. 2001. Genetic diversity and relationships in Malus sp. germplasm collections as determined by randomly amplified polymorphic DNA. J. Amer. Soc. Hort. Sci. 126:318-328.

Pontikis C. 2000. Subtropical and tropical fruits: Olive (in Greek). Stamoulis Publ. Athens, Greece.

Pontikis, C., M. Loukas, and G. Kousounis. 1980. The use of biochemical markers to distinguish olive cultivars. J. Hort. Sci. 54:333-343.

Prevost, G. and S. Mostardini. 1999. The scholarly study and botanical classification of the olive. Olivæ 78:60-77.

Rolhf M. 1998. NTSYSpc. Numerical taxonomy and multivariate analysis system. Version 2.02i. Dept. of Ecol. and Evol. State Univ. of New York, Setauket, N.Y.

Rotondi, A., M. Magli, C. Ricciolini, and L. Baldoni L. 2003. Morphological and molecular analyses for the characterization of a group of Italian olive cultivars. Euphytica 132:129-137.

Sharma, S. 1995. Applied multivariate techniques. Wiley, New York.

Wiesman, Z., N. Avidan, S. Lavee, and B. Quebedeaux. 1998. Molecular characterization of common olive varieties in Israel and the West Bank using randomly amplified polymorphic DNA (RAPD) markers. J. Amer. Soc. Hort. Sci. 123:837-841. 